\title{
LIMITED VEGETATIVE COMPATIBILITY AS A CAUSE OF SOMATIC RECOMBINATION IN Trichoderma pseudokoningii
}

\section{Fernando Gomes Barcellos ${ }^{1 *}$, Mariangela Hungria ${ }^{2}$, Aline Aparecida Pizzirani-Kleiner ${ }^{3}$}

\author{
Universidade Paranaense, Umuarama, PR, Brasil ${ }^{1}$; Embrapa Soja, Londrina, PR, Brasil² ; Departamento de Genética, Escola
} Superior de Agricultura “Luiz de Queiroz”, Piracicaba, SP, Brasil'.

\begin{abstract}
With the aim of a better characterization of the somatic recombination process in Trichoderma pseudokoningii, a progeny from crossings between T. pseudokoningii strains contrasting for auxotroph markers was characterized by RAPD markers and PFGE (electrophoretic karyotype). Cytological studies of the conidia, conidiogenesis and heterokaryotic colonies were also performed. The genotypes of the majority of the recombinant strains analyzed were similar to only one of the parental strains and the low frequency of polymorphic RAPD bands suggested that the nuclear fusions may not occur into the heterokaryon. In some heterokaryotic regions the existence of intensely staining hyphae might be related to cell death. We proposed that a mechanism of somatic recombination other than parasexuality might occur, being related to limited vegetative compatibility after postfusion events, as described for other Trichoderma species.
\end{abstract}

Key words: Somatic recombination; Limited vegetative compatibility; Trichoderma pseudokoningii; Parasexuality

\section{INTRODUCTION}

Since the description of recombination via the parasexual cycle in Aspergillus nidulans $(39,40)$, the occurrence of recombination events via parasexual processes has been described for most fungal species investigated so far $(12,16)$. However, the different stages of the parasexual recombination process may vary considerably among different fungal species $(12,16)$. In many cases, as some steps of the parasexual process have not been detected yet, they were considered transient (16), whereas in other fungi, the diploid phase has not been identified and the recombinants were obtained directly from the heterokaryon $(4,9)$. This last process was called parameiosis (9) and was described in many fungi species, e.g. Acremonium chrysogenum (5), Cephalosporium acremonium (6), Aspergillus niger (9), Metarhizium anisopliae (4), Cladosporium fulvum (2), Trichoderma pseudokoningii (35) and Beauveria bassiana $(8,36)$.

\footnotetext{
*Corresponding Author. Mailing address: Universidade Paranaense, Laboratório de Biologia Molecular, Praça Mascarenhas de Moraes, 4282, Umuarama, PR, Brasil, CEP 87502-210.; E-mail: fernandobarcellos@unipar.br; fgbarcel@yahoo.com.br
} 
In several fungal species the obtention of recombinants via processes other than the sexual (meiotic divisions) or parasexual cycles (reductional mitotic divisions) has been described, and transference between nuclei, in stable or transient heterokaryons, of transposons, plasmids, chromosomal fragments and also whole chromosomes has been observed $(11,15,16)$.

Whithin the Trichoderma genus there are descriptions of obtention of recombinants directly from the heterokaryon between strains of several species, which were formed by means of hyphal anastomosis, protoplast fusion or nuclear transfers $(3,7,23,37,38,46,47,48,49,50)$. In several experiments with Trichoderma, the occurrence of characteristic patterns has been observed and would be related to some level of vegetative incompatibility or due to limited vegetative compatibility $(5,46,48,49)$. The unstable recombinants obtained in those crosses showed that the majority of the markers were similar to only one of the parental strains, and in general the recombinants also showed irregular colony borders and frequently originate sectors of vigorous growth $(3,47,48)$.

Stasz \& Harman (47) have characterized several progenies from intra- and interstrain crosses (protoplast fusions) of $T$. harzianum, T. hamatum, T. koningii, and T. viride, with the objective of verifying whether the parasexuality or other genetic mechanisms were occurring in those fungi. In the interstrain crosses (between strains of the same or different species) the somatic hybrids developed very slowly and were considered as weakly prototrophic; furthermore, they were unstable and frequently developed sectors which gave rise to progeny strains showing a variety of morphotypes (47). Almost all progeny strains analyzed showed isozyme phenotypes identical to either one or other of the parental strains, despite the large variation in morphotypes and nutritional requirements. The authors concluded that the progenies have not originated from parasexual recombination mechanisms, and suggested that nuclear degradation from one of the parents (non prevalent parent) into the heterokaryon occurred, and that small portions of this genome might have been incorporated into the nuclear genome of the other parent (prevalent parent) (48). It has also been suggested that similar mechanisms might naturally occur following hyphal anastomosis or other mechanisms of plasmogamy, and that these events of nuclear degradation and incorporation of nuclear fragments into prevalent strain nuclei might be related to limited vegetative compatibility after postfusion events $(48,49)$.

There are some reports of the obtention of recombinant progeny of $T$. pseudokoningii directly from the heterokaryon, by hyphal anastomosis or protoplast fusion, in which almost all progeny strains showed the auxotrophic markers from only one of the parents $(3,7,23)$. As described by Stasz \& Harman (48), the same pattern of recombinant progeny strains is frequently obtained from heterokaryons in several crosses between $T$. pseudokoningii contrasting strains $(3,7)$.

This unknown mechanism of somatic recombination may thus naturally occur in the Trichoderma species and also in species from other genera, such as Beauveria (8, 14, 36), Metarhizium (4), Penicillium (19) and Alternaria (51).

In a previous work, we conducted crossing experiments via hyphal anastomosis between two $T$. pseudokoningii strains with contrasting auxotrophic markers, aiming at characterizing the somatic recombination in this species (7). A total of 1,052 colonies obtained from conidial suspensions of heterokaryotic colonies from four crosses were analyzed, and most were unstable through subculture and characterized by irregular colony borders, sparse sporulation and frequent sector formation. All recombinant colonies obtained were morphologically similar and had the same auxotroph markers of one of the parental strains (parent 12L) (7). Due to the instability through subculturing of the recombinant progeny and the similarity to only one of the two parental strains, the authors suggested that a mechanism of somatic recombination might be occurring, as proposed by Satsz \& Harman (48).

In this study, recombinant colonies from crosses between T. pseudokoningii contrasting strains previously obtained by 
Barcellos \& Pizzirani-Kleiner (7) were analyzed by random amplified polymorphic DNA (RAPD) and pulsed field gel electrophoresis (PFGE). Cytological studies of conidiogenesis, conidia and heterokaryotic colonies were performed aiming at better characterizing the recombination process (somatic recombination) in $T$. pseudokoningii, what may contribute to a more efficient application of inter- and intrastrain crossing methods in breeding programs.

\section{MATERIALS AND METHODS}

\section{Strains and growth conditions}

The T. pseudokoningii strains used in this study and the growth conditions were described previously (7). The recombinant strains analyzed by RAPD and PFGE were isolated directly from four different heterokaryotic colonies and the parental strains used in the crosses were complementary mutants for four auxotrophic markers (lysine, arginine, nicotinic acid and inositol) obtained by ultraviolet mutagenesis (7).

\section{Heterokaryon formation via anastomosis}

The protocol used for heterokaryon formation among the contrasting $T$. pseudokoningii parental strains was as described by Barcellos \& Pizzirani-Kleiner (7). The two parental strains used in the crosses are vegetatively compatible and therefore they belong to the same vegetative compatibility group (VCG), as described by Barcellos \& Pizzirani-Kleiner (7).

\section{RAPD analysis}

For DNA extraction, parental and recombinant strains were grown in $\mathrm{CM}$ broth medium (39) for 24 to $30 \mathrm{~h}$ at $37^{\circ} \mathrm{C}$, with shaking (150 rpm). After growth, the mycelium was filtered in a Büchner funnel with a disc of filter paper and washed with sterile distilled water. The mycelium was weighed, ground in liquid nitrogen, and the DNA was extracted as described by Raeder \& Broda (42). Three replicates of DNA from each strain were used for amplifications. RAPD analysis was carried out in a final volume of $30 \mu \mathrm{L}$ containing: $15 \mathrm{ng}$ of DNA template; $3.4 \mathrm{mM} \mathrm{MgCl}$; $2 \mathrm{U}$ Taq DNA polymerase (Invitrogen, Carlsbad, California); $0.25 \mathrm{mM}$ of each dNTP; 0.4 $\mathrm{mM}$ of primer (Operon Technologies, Alameda, CA) in $20 \mathrm{mM}$ Tris- $\mathrm{HCl} \mathrm{pH} 8.4$ containing $50 \mathrm{mM} \mathrm{KCl}$. PCR amplifications were conducted with an initial denaturation at $94^{\circ} \mathrm{C}$ for $5 \mathrm{~min}$, followed by forty PCR amplification cycles consisting of denaturing at $92^{\circ} \mathrm{C}$ for $1 \mathrm{~min}$, annealing at $35^{\circ} \mathrm{C}$ for $1 \mathrm{~min}$, and extension at $72^{\circ} \mathrm{C}$ for $2 \mathrm{~min}$, and finishing with an extension cycle of $5 \mathrm{~min}$. The amplification products were separated by electrophoresis in $1.4 \%$ agarose gels and visualized after ethidium bromide staining. All reactions were repeated at least twice and negative controls without DNA were always included. The profiles obtained were confirmed in triplicate.

\section{Reamplification of selected RAPD bands from agarose gels}

The selected RAPD bands were excised from agarose gels and purified with the use of the QIAquick gel extraction kit (Qiagen Inc., Valencia, California). The reamplification reactions were performed as described above with the use of the same RAPD primers and $5 \mu \mathrm{l}$ of the purified DNA suspension. The reamplified bands were purified with the QIAquick PCR purification kit (Qiagen Inc.).

\section{Sequencing and BLAST analysis of reamplified selected RAPD bands}

The reamplified and purified RAPD bands were cloned into the pGEMT - Easy Vector (Promega, Madison, Wisconsin) using the manufacturer's protocol. The cloned RAPD bands were sequenced following the pGEMT - Easy Vector (Promega) protocol, using the DYEnamic ET terminator chemistry (GE Healthcare, Piscataway, NJ) and analyzed in a MegaBace 1000 DNA Analysis System (GE Healthcare), following the parameters described by Menna et al. (33). The high-quality sequences obtained in both $3^{\prime}$ and 5' directions were assembled using the programs phred $(20,21)$, 
phrap (http://www.phrap.org) and Consed (27), and were submitted to the GenBank (http://www.ncbi.nlm.nih.gov/blast) database seeking for significant alignments. The GenBank accession numbers EU658931 and EU658933 were assigned to the cloned RAPD band sequences determined in this study.

\section{Preparation of intact chromosomal DNA}

For protoplast production, conidia from $T$. pseudokoningii strains were inoculated on plates containing CM medium (41) and incubated for 7 days at $28^{\circ} \mathrm{C}$. After growth, a conidial suspension was prepared (approximately $10^{9}$ conidia $/ \mathrm{mL}$ ) in a $0.1 \%$ Tween 80 solution. One $\mathrm{mL}$ of this suspension was added into an erlenmeyer flask containing $50 \mathrm{~mL}$ of $\mathrm{CM}$ broth and incubated for $18 \mathrm{~h}$ at $28^{\circ} \mathrm{C}$ with shaking (150 rpm). The mycelium was collected by filtration in a Büchner funnel with a disc of filter paper, washed twice with $0.6 \mathrm{M}\left(\mathrm{NH}_{4}\right)_{2} \mathrm{SO}_{4} \mathrm{pH}$ 5.8 , dried and weighed. For each mg of mycelium dry weight, $20 \mu \mathrm{L}$ of $0.6 \mathrm{M}\left(\mathrm{NH}_{4}\right)_{2} \mathrm{SO}_{4} \mathrm{pH} 5.8$ and the lytic enzyme (Lysing Enzymes from Trichoderma harzianum - SIGMAALDRICH, St. Louis, Missouri) were added at a proportion of $5 \%$ of the mycelium dry weight. The lysis mixture was incubated for $3 \mathrm{~h}$ at $28^{\circ} \mathrm{C}$ with shaking (50 rpm). After protoplast production, the suspension was filtered through a 50 $\mu \mathrm{M}$ nylon mesh and the filtrate was centrifuged at 4,000 rpm for $5 \mathrm{~min}$. The supernatant was discarded and the precipitate was resuspended in $0.6 \mathrm{M}\left(\mathrm{NH}_{4}\right)_{2} \mathrm{SO}_{4} \mathrm{pH}$ 5.8. Protoplasts were washed twice and their number was estimated with a Neubauer counting chamber. Finally, protoplasts were resuspended to reach a final concentration, including the Low Gelling Temperature (LGT) agarose $1.4 \%$ (A 4018 - SIGMAALDRICH, St. Louis, Missouri), of 2 to $4 \times 10^{8}$ protoplasts $\mathrm{mL}^{-1}$ and were maintained at $42^{\circ} \mathrm{C}$. An equal volume of a 0.6 $\mathrm{M}$ solution of $\left(\mathrm{NH}_{4}\right)_{2} \mathrm{SO}_{4} \mathrm{pH} 5.8$ containing agarose LGT $1.4 \%$ was prepared, heated to complete dissolution and maintained at $42^{\circ} \mathrm{C}$. Equal volumes of the two solutions were mixed, homogenized and pipetted into $2 \mathrm{~mm} \times 1 \mathrm{~cm} \mathrm{x} 2 \mathrm{~cm}$ plug moulds. The plugs were solidified at $4^{\circ} \mathrm{C}$ for $15 \mathrm{~min}$ and placed in NDS buffer $(10 \mathrm{mM}$ Tris-HCl; $0.5 \mathrm{M}$ EDTA; $1 \% \mathrm{~N}$ lauroylsarcosine, $\mathrm{pH} 9.5$ ) containing $1 \mathrm{mg} \mathrm{mL}^{-1}$ proteinase $\mathrm{K}$ (Invitrogen). The plugs were incubated in this solution at $50^{\circ} \mathrm{C}$ for $18 \mathrm{~h}$. The NDS buffer was then discarded, a $0.5 \mathrm{M}$ solution of EDTA pH 8.0 was added and maintained at $50^{\circ} \mathrm{C}$ for $30 \mathrm{~min}$. The EDTA solution was substituted and maintained at room temperature for $30 \mathrm{~min}$. This procedure was repeated once and the plugs were stored in $0.5 \mathrm{M}$ EDTA pH 8.0 at $4^{\circ} \mathrm{C}$ until used.

Separation of chromosome-sized DNA molecules of $T$. pseudokoningii by Pulsed Field Gel Electrophoresis (PFGE)

Chromosomal separations were carried out in a ContourClamped Homogeneous Electric Field (CHEF) system (DR-III, Bio-Rad, Hercules, California). The electrophoresis was performed in $0.7 \%$ agarose gels (A-2929, SIGMA) in $0.5 \mathrm{X}$ TBE buffer (50 mM Tris, $50 \mathrm{mM}$ boric acid, $1 \mathrm{mM}$ EDTA, $\mathrm{pH}$ 8.0). The agarose plugs containing the chromosomal DNA were cut to appropriate sizes, placed inside the gel wells, and sealed with $0.8 \%$ agarose. Gels were run at $12^{\circ} \mathrm{C}$ in $0.5 \mathrm{X}$ TBE buffer at $44 \mathrm{~V}$ (constant current) for $168 \mathrm{~h}$ with pulse intervals of 1800-5400 s (linear ramp). The gels were stained with ethidium bromide $\left(0.5 \mu \mathrm{g} \mathrm{mL}^{-1}\right)$ for $60 \mathrm{~min}$, destained for 60 $90 \mathrm{~min}$, and visualized under UV light and photographed. Densitometric analysis of the ethidium bromide-stained pattern of the chromosomal bands was performed using the Bionumerics software (Applied Mathematics, Kortrijk, Belgium, version 4.6). The chromosomal size was determined using a T. pseudokoningii wild type strain (3L) as the chromosome-sized DNA standard (35).

Nuclear staining of conidiogenesis, conidia and heterokaryotic colonies with the use of the HCl-Giemsa method

Nuclear staining of conidiogenesis, conidia and heterokaryotic colonies was performed by the HCl-Giemsa method (52). Conidia were stained after being attached to a coverslip with one drop of albumin solution and dried. For the 
conidiogenesis staining, dialysis membranes were put over plates containing CM medium, and the conidia were incubated over them. After periods of 20, 32 and $72 \mathrm{~h}$ the membranes were taken from the plates and stained on clean slides. To the heterokaryotic colonies nuclear staining, dialysis membranes were placed around a central well previously done in the solid agar plate, and after periods of 2, 4 and 7 days, accordingly to the development of the heterokaryotic colonies, the membranes were removed and stained.

For the staining, an ethanol-acetic acid $(3: 1 \mathrm{v} / \mathrm{v})$ solution was used for fixation for $30 \mathrm{~min}$ at room temperature. The hydration was done in ethanol $95 \%$ for $5 \mathrm{~min}$ (three times), followed by ethanol $70 \%$ for $30 \mathrm{~min}$. The hydrolysis was done with $\mathrm{HCl} 1 \mathrm{~N}$ at $60^{\circ} \mathrm{C}$ for $12 \mathrm{~min}$. The coverslips (or dialysis membranes) were washed three times in distilled water and stained by immersion in the Giemsa stain $(0.07 \%$ Giemsa in 50 $\mathrm{mM}$ phosphate buffer, $\mathrm{pH} 7.0,3 \%$ glycerol, $3 \%$ methanol) for 20 to $30 \mathrm{~min}$. The coverslips were then rinsed with phosphate buffer to wash the excess of Giemsa stain, mounted on clean glass slides and observed by light microscopy.

\section{RESULTS AND DISCUSSION}

\section{RAPD analysis of the recombinant colonies}

Ninety-seven RAPD primers were initially screened to distinguish the two contrasting strains of $T$. pseudokoningii used in the crosses, and 17 primers which showed good polymorphism were chosen for the analysis of the recombinants. With the majority of the primers used, one of the parental strains (parental 12L) showed the same banding pattern of the other parental and at least an additional band (data not shown).

Fifty out of the 111 recombinant colonies originally obtained (7) were then analyzed by RAPD. The results obtained with two out of the 17 primers used are shown in
Figure 1. With all primers used, all recombinants showed similar band profiles (Fig 1A), but some primers allowed the detection of one or more polymorphic bands (Fig 1B). All recombinants have always shown band patterns similar to only one of the parental strain (9L), with the absence of the additional band observed in the other parental strain (12L). These results contrast with the morphological appearance of the recombinant colonies, which were similar to parental strain 12L (7). The parental strain 12L showed instability when grown in non-selective media, and after successive generations the additional RAPD bands observed with almost all primers were lost (data not shown).

When primer P19 was used, a polymorphic band of about $850 \mathrm{bp}$ was observed in the recombinants but not in the parental strains (Fig 1B). Also, the parental strains had two bands of high molecular weight that were not present in many of the recombinant strains.

Stasz \& Harman (48) conducted isozyme analyses with over 1,000 progeny strains from intra- and interspecies crosses of Trichoderma via protoplast fusion. In all analyses, the isozyme patterns of the recombinants were always identical to only one of the parental strains.

Durand et al. (19) analyzed, also with RAPD markers, a recombinant progeny of Penicillium roquefortii obtained via protoplast fusion. The majority of the recombinant strains showed band patterns identical to only one of the parental strains. Additional bands, absent in the parental strains, were also observed in the recombinant strains and with one of the primers it was possible to detect bands in the parental strains that were not present in the recombinants.

Dalzoto et al. (14) evaluated by RAPD recombinant strains of Beauveria bassiana obtained from different heterokaryons, and have also observed that the majority of the recombinant strains had band patterns identical to only one of the parental strains involved in the crosses. 
A
M
R
$912 \mathrm{M}$

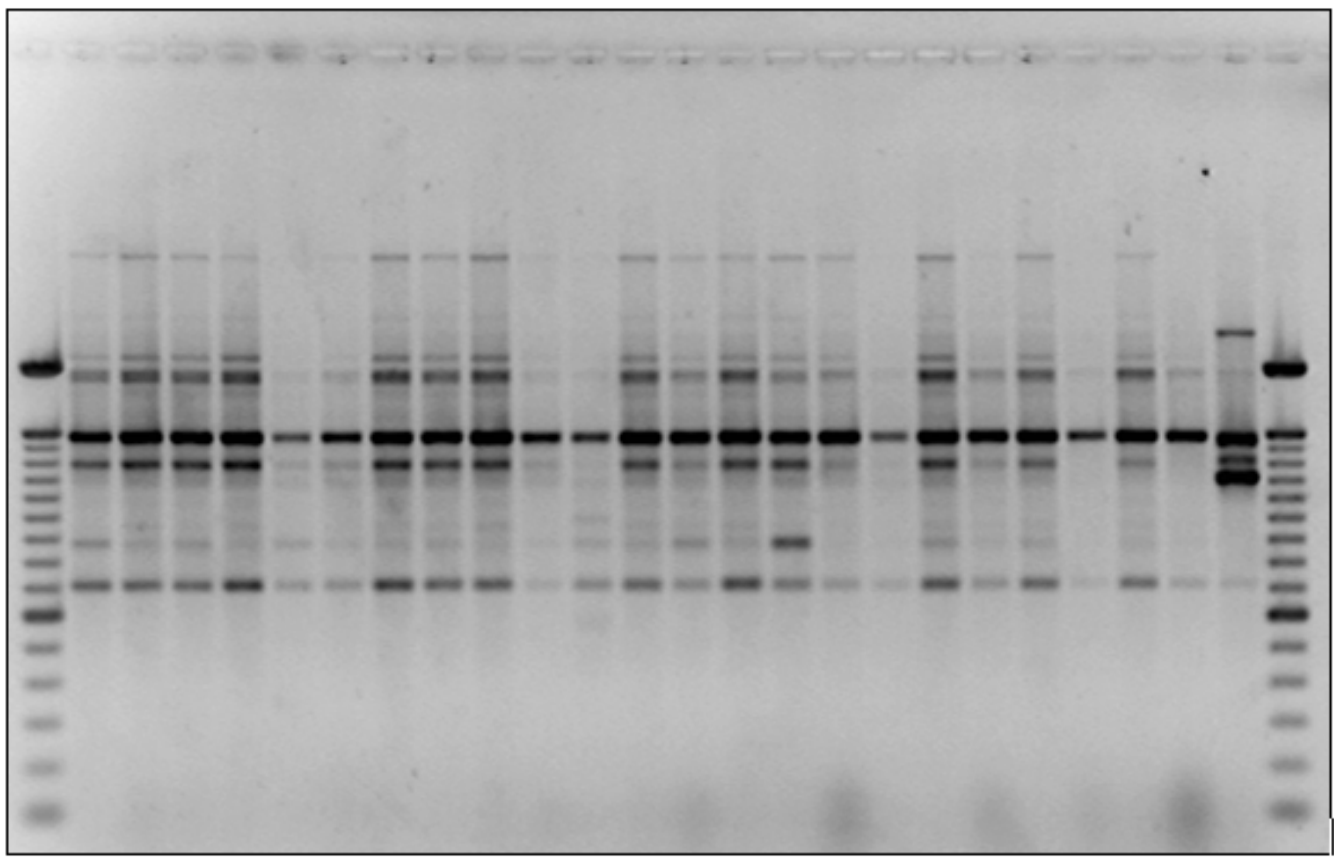

B

M

$\mathrm{R}$

$912 \mathrm{M}$

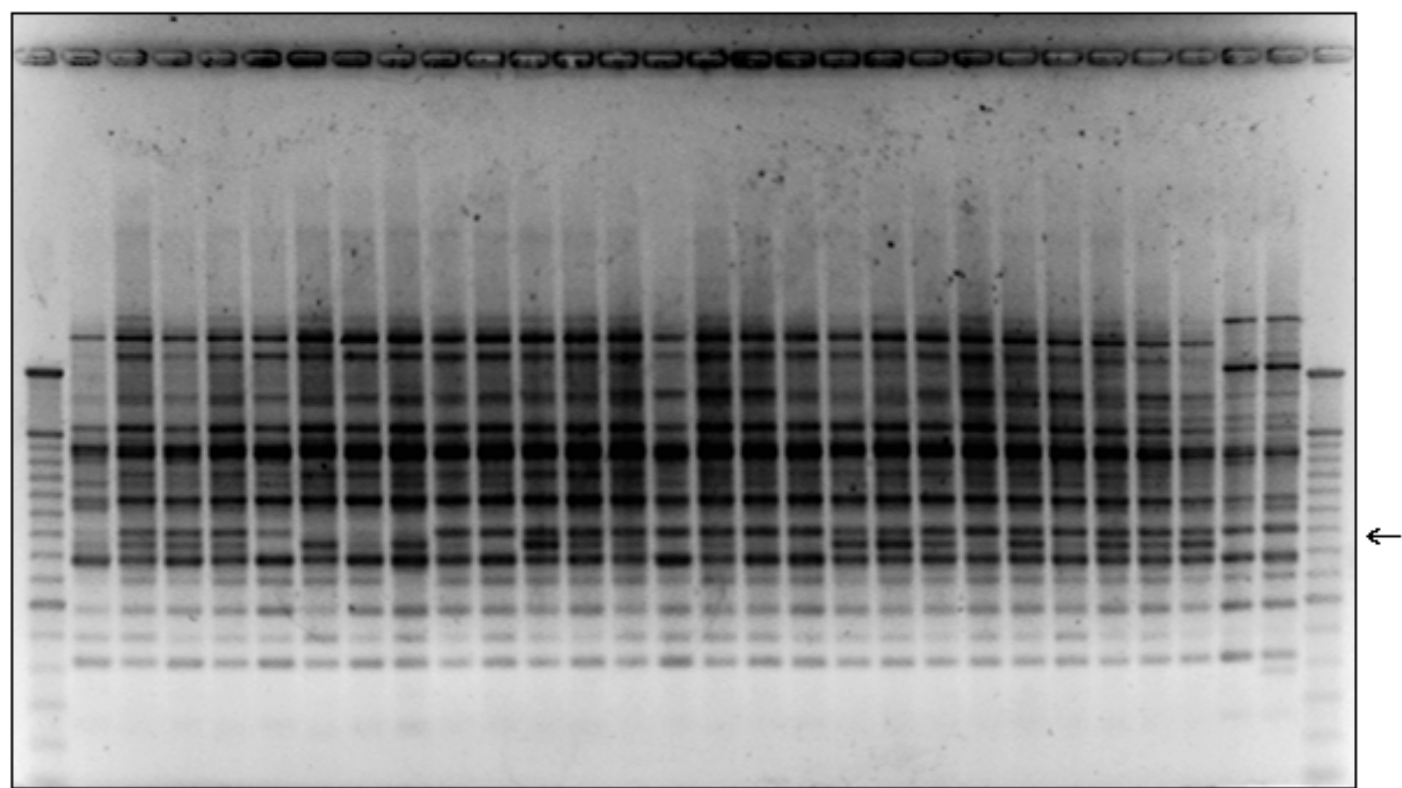

Figure 1. RAPD analyses of the parental (9L and 12L) and recombinant strains (R). A - primer AX03; B - primer P19; 9 and 12 parental strains 9L and 12L, respectively; R - recombinant strains; M - Ladder 100 bp (Invitrogen); Arrow - polymorphic band not present in parental strains. 


\section{Separation of chromosome-sized DNA molecules} (electrophoretic karyotype) of parental and recombinant $T$. pseudokoningii strains by PFGE

The chromosomes of the parental (9L and 12L) and five recombinant strains were separated by PFGE (Fig 2). In relation to the chromosomal pattern analysis, four out of the five recombinant strains (9R, 23R, 12R and 25R) were similar to the parental strain $12 \mathrm{~L}$ and one (45R) had a distinct chromosomal band pattern (Fig 2).

These results are in agreement with the morphological and auxotrophic markers analyses, where the majority of the recombinant strains obtained from the crosses, including the recombinant strains analyzed by PFGE, were similar to the parental $12 \mathrm{~L}$ (7). Even though the $45 \mathrm{R}$ strain had a different chromosomal pattern from the parental 12L, it had similar morphological properties and auxotroph markers (7).

Therefore, the recombinant strains, as evidenced by PFGE, are genotypically similar to the parental strain 12L. From the 17 primers used, only one has shown a polymorphic band in the recombinant strains that was not present in their parents. These two observations, of dominance of one parental genotype and of the low frequency of polymorphic RAPD bands suggest that the nuclear fusions necessary to the parasexual events of recombination did not occur in the heterokaryotic mycelia.

\section{$\begin{array}{lllllllll}9 \mathrm{~L} & 12 \mathrm{~L} & 9 \mathrm{R} & 23 \mathrm{R} & 12 \mathrm{R} & 45 \mathrm{R} & 25 \mathrm{R} & 3 \mathrm{~L}\end{array}$}

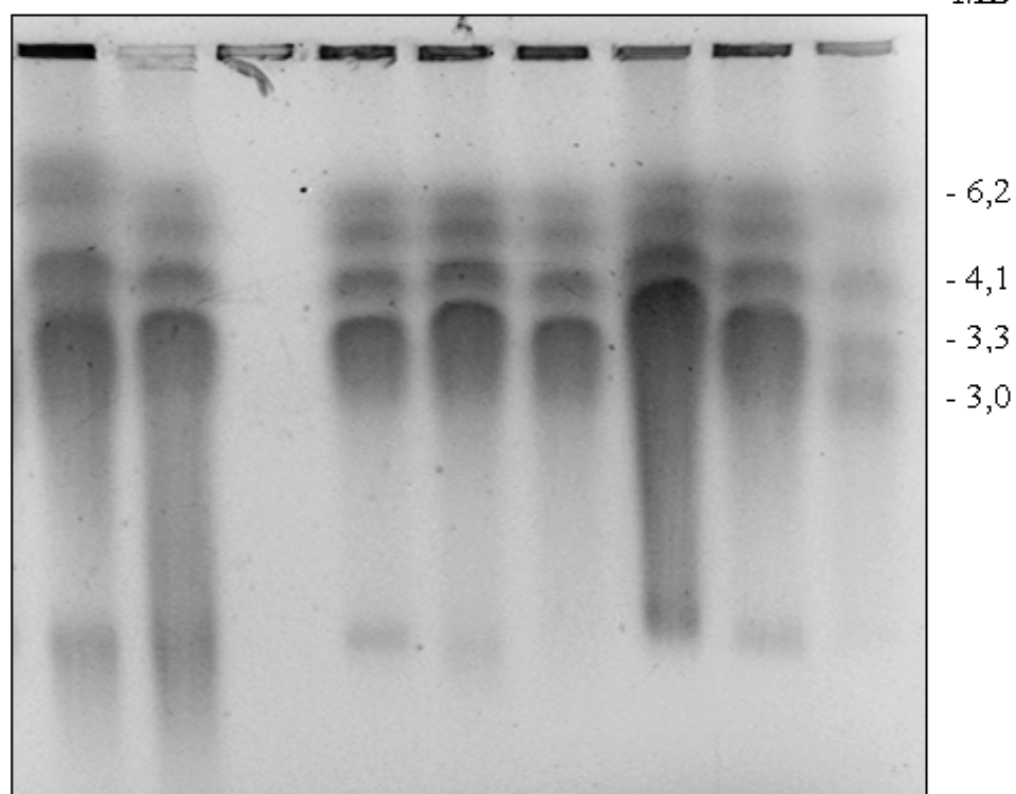

Figure 2. A - Electrophoretic karyotype of T. pseudokoningii parental (9L and 12L) and recombinant strains (9R, 23R, 12R, 45R and 25R). 3L - T. pseudokoningii wild type strain used as molecular weight standard (Nadalini 1997); Mb - Molecular weight in megabases.

\section{Sequencing of selected RAPD bands}

Two RAPD bands that were present in the parental strain $12 \mathrm{~L}$ and absent in $9 \mathrm{~L}$ and in the recombinant strains were excised from the agarose gels, cloned, sequenced and compared with sequences deposited in the GenBank database.
High levels of similarity were detected for two known proteins (Table 1). The sequence obtained after amplification with primer $\mathrm{P} 7$ has shown higher similarity (78\%) to the protein sequence of a gamma-aminobutiric acid (GABA) transport protein of Candida albicans. In Sacharomyces 
serevisiae, the UGA4 gene, which showed homology to GABA/polyamine transporter gene from $C$. albicans, encodes the gamma-aminobutyric acid (GABA) and $\delta$-aminolaevulinic acid (ALA) permease and its expression is regulated by the $\mathrm{N}$ and $\mathrm{C}$ source (31). The UGA4 protein is located at the vacuolar membrane and catalyses the transport of the gammaaminobutyric acid (GABA) and putrescine (53). The gamma- aminobutyric acid (GABA) transport protein in S. serevisiae supports cell growth with the GABA as the sole N source and, therefore, may also be related to adaptation to starvation (31, 53). It was demonstrated that the expression of the $U G A 4$ gene is repressed by extracellular amino acids and is mediated by a multicomponent amino acid sensor complex known as SPS sensor, localized at the plasma membrane (34).

Table 1. Similarity of the RAPD band sequences to protein sequences deposited on GenBank database with the use of Blast $\mathrm{x}$ program (NCBI)

\begin{tabular}{|c|c|c|c|c|c|c|c|}
\hline \multirow{2}{*}{$\begin{array}{l}\text { RAPD band } \\
\text { sequence }^{1}\end{array}$} & \multirow{2}{*}{$\begin{array}{l}\text { RAPD } \\
\text { primers }^{2}\end{array}$} & \multirow{2}{*}{$\begin{array}{l}\text { Length } \\
(\text { bp) }\end{array}$} & \multicolumn{5}{|c|}{ Significant similarities with known proteins } \\
\hline & & & $\begin{array}{c}\text { Identity } \\
(\%)\end{array}$ & $\begin{array}{c}\text { Lenght }^{4} \\
\text { (aa) }\end{array}$ & Protein description & GenBank $^{5}$ & $\begin{array}{c}\text { Lenght }^{6} \\
\text { (aa) }\end{array}$ \\
\hline EU658931 & P7 & 219 & 77 & 54 & $\begin{array}{l}\text { gamma-aminobutyric acid (GABA) } \\
\text { transport protein (Candida albicans) }\end{array}$ & $\overline{X P \_715361}$ & 544 \\
\hline EU658933 & A7 & 400 & 80 & 106 & Rvs167 protein (Candida albicans) & XP 710580 & 474 \\
\hline
\end{tabular}

${ }^{1}$ GenBank accession number

${ }^{2}$ RAPD primers used for the amplifications

${ }^{3}$ Length in bp of the RAPD band sequence deposited in the database

${ }^{4}$ Length in aa that showed similarity with the protein sequences deposited in the database

${ }^{5}$ GenBank accession number of the protein sequences from database that showed significant similarities

${ }^{6}$ Length in aa of the protein sequences from database that showed significant similarities

The sequence obtained after amplification with primer A7 showed high similarity ( $81 \%$ ) to the Rvs167 protein sequence of Candida albicans. In S. cerevisiae the Rvs167 protein forms a heterodimer with the Rvs161 protein and plays a role in the regulation of the actin cytoskeleton, endocytosis, sporulation, vesicle trafficking and targeting at the plasma membrane, cell wall synthesis, cell polarity and integrity $(10,22)$. A $S$. cerevisiae rvs161 mutant strain was characterized as being sensitive to $\mathrm{N}, \mathrm{S}$ and $\mathrm{C}$ starvation, showing an increased proportion of budded cells and differing in cell morphology (13). It was observed that Rvs161 and Rvs167 proteins have a shared role in both growing and mating cells and that they function together in vegetative cells and during the mating response (28). Also, there are evidences of the role of the Rvs161-167p heterodimer in the adaptation to $\mathrm{N}, \mathrm{S}$ and $\mathrm{C}$ starvation (13). Both proteins could then have possible functions in vegetative incompatibility reaction in Trichoderma and other fungal species.

The two putative proteins identified in this study may represent heteroallelic loci and could be related to vegetative incompatibility systems in T. pseudokoningii. In filamentous fungi, the vegetative compatibility is controlled by incompatibility systems and the viability of heterokaryons is genetically controlled by specific loci termed het (for heterokaryon incompatibility) or vic (for vegetative incompatibility) $(24,25,26,45)$. A het can be defined as a locus in which heteroallelism cannot be tolerated in a heterokaryon, and heterokaryotic fusion cells from individuals differing in one or more het loci are usually compartmentalized and undergo death by a lytic process $(25,26,45)$. A number of 
het loci has been characterized from several fungal species and it was evidenced that they encode very different, nonhomologous proteins $(24,25,26,45)$. In Podospora anserina, the incompatibility can be triggered by the coexpression of two proteins that differ by only one amino acid (45). Sarkar et al (44) studied the molecular mechanism of non-self recognition mediated by allelic differences at het-c and have shown that the non-self recognition is mediated by the physical interaction of HET-C polypeptides encoded by het-c alleles of alternative specificity. The HET-C heterocomplex was specifically localized at the plasma membrane of dead hyphal compartments.

There is increasing evidence of a connection between the incompatibility reaction and the cellular response to nutrient starvation $(17,18,24,45)$. Cell death due to incompatibility in fungi seems to result from similar mechanisms of programmed cell death (PCD), as in higher eukaryotes, and apparently the cellular program leading to PCD in fungi employs components of the cellular machinery required for adaptation to starvation $(18,24,43)$. There is also evidence that PCD may be linked to actin and the cytoskeleton in filamentous fungi (43), and mutations decreasing actin turnover lead to an accumulation of reactive oxygen species (ROS) and induced $\operatorname{PCD}(28,43)$.

\section{Cytological studies of the conidiogenesis, conidia and heterokaryotic colonies with the use of the HCl-Giemsa method}

Cytological studies with the HCl-Giemsa method for nuclear staining were performed to characterize the nuclear distribution in conidiogenesis, the number of nuclei in the mature conidia of both $T$. pseudokoningii parental strains, heterokaryotic colonies and some recombinant strains, and to study hyphal anastomosis and nuclear behavior during the process of formation of heterokaryotic colonies. These cytological studies were necessary for a better interpretation of the genetic analysis of the crosses previously described.

The mature conidia from the parental strain $12 \mathrm{~L}$, heterokaryotic colonies, and recombinant strains contained from one to three or more nuclei, and all conidia from parental strain 9L were uninucleated (Fig 3A). Stasz et al. (50) described the occurrence of multinucleated conidia in strains of Trichoderma harzianum and Furlaneto \& Pizzirani-Kleiner (23) observed that recombinant prototroph strains of $T$. pseudokoningii, obtained from crosses via protoplast fusion had binucleated conidia.

In order to characterize the origin of the different nuclei observed in the mature conidia, the distribution of the nuclei during the conidiogenesis was studied in the parental strain $12 \mathrm{~L}$, heterokaryotic colony and in one recombinant strain (Fig 3B). The conidia formed on each phialide contained only one nucleus and the release of conidia from phialide was initiated after conidia formation. Hammil (29) studied the conidiogenesis in T. saturnisporum by electron transmission microscopy and observed uninucleated phialides and the formation of uninucleated conidia.

Therefore, the existence of mature conidia containing two or more nuclei probably relates to mitotic divisions occurring after conidial formation, and hence they are homokaryotic with all nuclei originating from only one nucleus. This fact excludes the hypothesis that the instability of the recombinant strains used in this study may be due to a colony origin from conidia of the heterokariotic colonies containing genotypically different nuclei.

In the cytological studies of heterokaryotic colonies, the presence of multinucleated hyphae containing entire nuclei was observed (Fig 3D; 1). However, in other hyphae the existence of a cytoplasmatic grainy material but not of the entire nuclei was observed (Fig 3D; 3). In some colony regions intensely staining hyphae were observed, which may be an evidence of some process of cell death (Fig 3D; 2). Hyphal anastomosis was observed in many colony regions (Fig 3C; 1 and 2), and in one particular region there was a nucleus apparently in active movement between connecting hyphae segments (Fig 3C; 2).

Jacobson et al. (30) employed optical and transmission 
electron microscopy to study the vegetative incompatibility reactions in two Neurospora crassa strains heterozygous (partial diploids) for two het (heterokaryon incompatibility) loci. They have verified that these strains, heterozygous at only one het loci, had a slow growth rate and about $15 \%$ of the cells randomly distributed in the colonies were dead or undergoing death; extensive organelle degradation and plasmolysis, as well as fragmentation of the cytoplasm into small membrane-bound bodies, were also reported. The hyphal regrowth into dying cells from adjacent healthy cells was frequently observed, with electron dense material surrounding the regrowth regions. As the regrowth occurred soon after the beginning of cellular degradation, remnants of organelles were visible at the electron dense region surrounding the new cells growing within the hyphae.

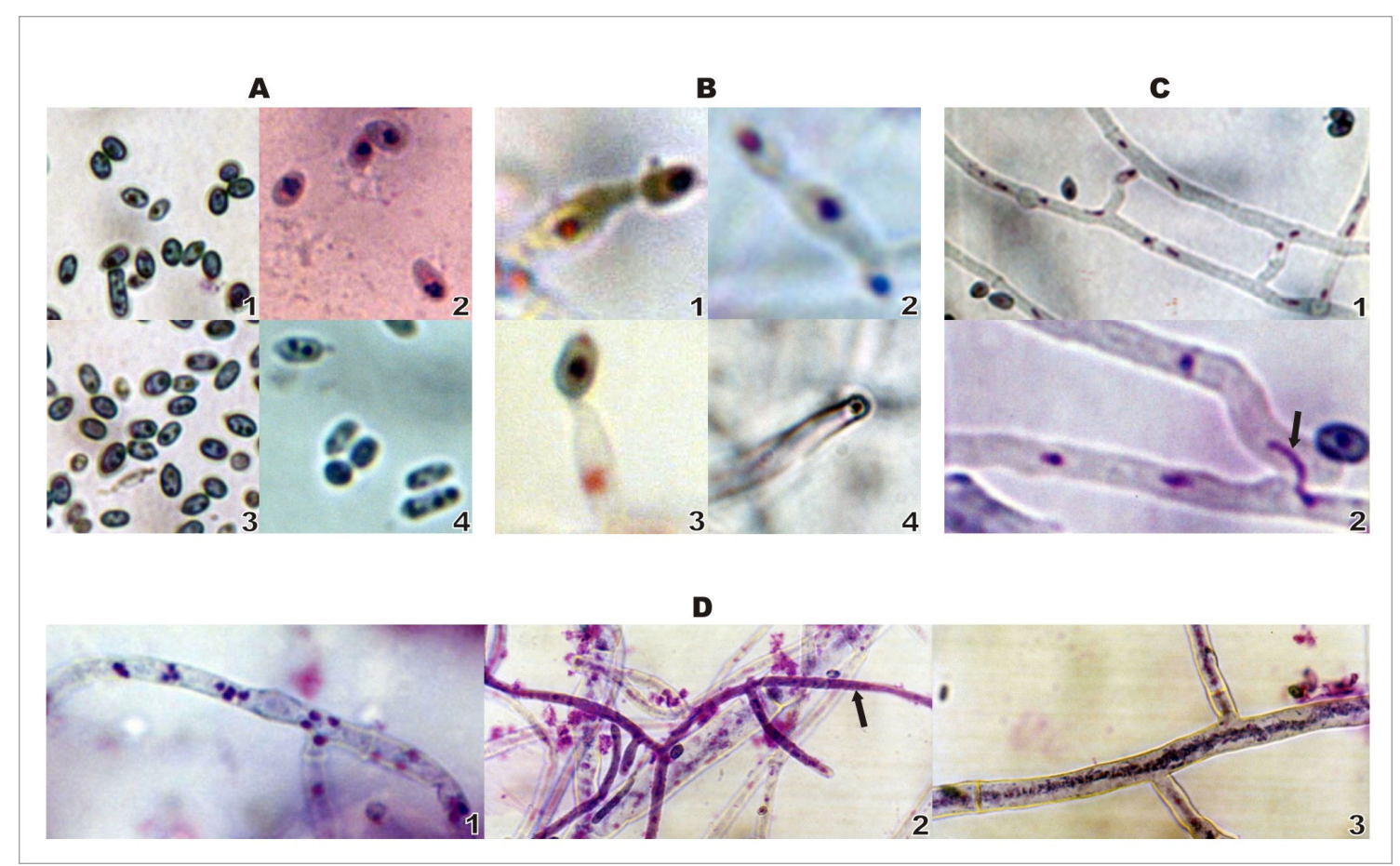

Figure 3. Nuclear staining of conidia, conidiogenesis, and of the heterokaryotic colony, with the HCl- Giemsa method. (A) Nuclear staining of conidia. 1 - parental strain 12L; 2 - parental strain 9L; 3 - heterokaryotic colony; 4 - recombinant strain 18 R. (B) Nuclear distribution of nuclei during the conidiogenesis. 1 - parental strain 12L; 2 and 3 - heterokaryotic colony; 4 recombinant strain 23R. (C) Nuclear staining at hyphal anastomosis regions in the heterokaryon. 1 - a region of contact and initial anastomosis process; 2 - anastomosis region showing a nucleus with an active movement (arrow); (D) Nuclear staining of heterokaryotic colony. 1 - multinucleated hyphae compartments containing integral nuclei; 2 - intensely stained hyphae (arrow), that may be an indication of a cellular death process; 3 - hyphal compartment showing a cytoplasmatic grainy material; (Magnification, 1,000 X).

Aimi et al. (1) observed cellular death process in some hyphae anastomosis regions in heterokaryons from crosses among Helicobasidium monpa strains from different vegetative compatibility groups. They reported hyphal segments intensely stained with ethidium bromide, evidencing cellular death due to vegetative incompatibility. 
The cytology of hyphal fusions between incompatible Neurospora crassa strains that differed in three het loci and the cytology of transformants containing incompatible het-c alleles, were studied by Marek et al. (32) with fluorescent DNA stains and terminal deoxynucleotidyl transferase-mediated d $\underline{U} T P-X$ nick end labeling (TUNEL). The hyphal fusions cells between het incompatible strains and hyphal segments in het-c incompatible transformants were compartmentalized by septal plugging and contained heavily degraded nuclear DNA. Furthermore, the cytoplasm in the plugged hyphal compartment first became granular and then highly vacuolated, and nuclei with DNA degradation (TUNEL-positive) were found in only one of the fusion cells.

The observation, in some heterokaryon regions, of the existence of hyphal segments containing grainy material with no detection of entire nuclei and the existence of intensely stained hyphal segments, may be an evidence of a cellular death process due to some level of vegetative incompatibility. Even though the heterokaryotic colonies analyzed in this study had a vigorous growth, some incompatibility may occur in the recombinant strains, as suggested by Stasz et al. (49) for other Trichoderma species.

Finally, the RAPD, PFGE and cytological analyses described here add more information to the initial characterization based on the auxotroph markers and on the morphological analysis of the recombinant progeny from crosses of $T$. pseudokoningii (7). These results strengthen the evidence that a mechanism of somatic recombination, other than parasexuality, may be occurring. Such mechanism might be as proposed by Stasz and Harman (48) to other Trichoderma species, where the pattern of recombinants obtained may be due to limited vegetative compatibility after postfusion events, resulting in the nuclear degradation from one of the two parental strains involved in the crosses and in the incorporation of chromosomal DNA fragments into the integral nuclei from the other parental strain.

\section{ACKNOWLEDGMENTS}

F. G. Barcellos acknowledges a research fellowship from CNPq (Conselho Nacional de Desenvolvimento Científico e
Tecnológico). The authors thank Ricardo S. Araujo for suggestions on the manuscript.

\section{REFERENCES}

1. Aimi, T.; Yotsutani, Y.; Morinaga, T. (2002). Cytological analysis of anastomoses and vegetative incompatibility reactions in Helicobasidium mompa. Curr. Microbiol. 44, 148-152.

2. Arnau, J.; Oliver, R. P. (1993). Inheritance and alteration of transforming DNA during an induced parasexual cycle in the imperfect fungus Cladosporium fulvum. Curr Genet 23, 508-511.

3. Bagagli, E.; Furlaneto, M. C.; Pizzirani-Kleiner, A.; Azevedo, J. L. (1995). Genetic recombinants in Trichoderma pseudokoningii (Rifai) without typical parasexuality. Can. J. Microbiol. 41, 1132-1134.

4. Bagagli, E.; Valadares, M. C. C.; Azevedo, J. L. (1991). Parameiosis in the entomopathogenic fungus Metarhizium anisopliae (Metsch) Sorokin. Rev. Bras. Genet. 14, 262-272.

5. Ball, C.; Hamlyn, P.F. (1978). The genetics of Acremonium chrysogenum. Rev. Bras. Genet. 1, 83-96.

6. Ball, C.; Hamlyn, P.F. (1982). Genetic recombination studies with Cephalosporium acremonium related to the production of the industrially important antibiotic Cephalosporin. Rev. Bras. Genet. 5, 113.

7. Barcellos, F.G.; Pizzirani-Kleiner, A. A. (2003). Genetic characterization of somatic recombination in Trichoderma pseudokoningii. Braz. J. Microbiol. 34, 152-156.

8. Bello, V. A.; Paccola-Meirelles, L. D. (1998). Localization of auxotrophic and benomyl resistance markers through the parasexual cycle in the Beauveria bassiana (Bals.) Vuill entomopathogen. J. Invertebr. Pathol. 72, 119-125.

9. Bonatelli Junior, R.; Azevedo, J. L.; Valent, G. V. (1983). Parasexuality in a citric acid producing strain of Aspergillus niger. Rev. Bras. Genet. 6, 399-405.

10. Breton, A. M.; Schaeffer, J.; Aigle, M. (2001). The yeast Rvs161 and Rvs 167 proteins are involved in secretory vesicles targeting the plasma membrane and in cell integrity. Yeast 18, 1053-1068.

11. Caten, C. E. (1981). Parasexual processes in fungi. In: Gull, K.; Oliver, S. G. (eds). The fungal nucleus. Cambridge University Press, Cambridge, UK, p.191-214.

12. Clutterbuck, A. J. (1996). Parasexual recombination in fungi. J. Genet. 75, 281-286.

13. Crouzet, M.; Urdaci, M.; Dulau, L.; Aigle, M. (1991). Yeast mutant affected for viability upon nutrient starvation: characterization and cloning of the RVS161 gene. Yeast 7, 727-743.

14. Dalzoto, P. R.; Glienke-Blanco, C.; Kava-Cordeiro, V.; Araújo, W. L.; Azevedo J. L. (2003). RAPD analyses of recombination processes in the 
entomopathogenic fungus Beauveria bassiana. Mycol. Res. 107, 10691074.

15. Day, A. W. (1998). Nonmeiotic mechanisms of recombination in the anther smut Microbotryum violaceum. Int. J. Plant Sci. 159, 185-191.

16. Debets, A. J. M. (1998). Parasexuality in fungi: mechanisms and significance in wild populations. In: Couteaudier, P. B. Y.; Clarkson, J. (eds.). Molecular variability of fungal pathogens. CAB International, New York, USA, p.41-53.

17. Dementhon, K.; Iyer, G.; Glass, N. L. (2006). VIB-1 is required for expression of genes necessary for programmed cell death in Neurospora crassa. Eukaryot. Cell 5, 2161-2173.

18. Dementhon, K.; Paoletti, M.; Pinan-Lucarré, B.; Loubradou-Bourges, N.; Sabourin, M.; Saupe, S. J.; Clavé, C. (2003). Rapamycin mimics the incompatibility reaction in the fungus Podospora anserina. Eukaryot. Cell 2, 238-246.

19. Durand, N.; Reymond, P.; Fèvre, M. (1993). Randomly amplified polymorphic DNAs assess recombination following an induced parasexual cycle in Penicillium roqueforti. Curr. Genet. 24, 417-420.

20. Ewing, B.; Green, P. (1998). Base-calling of automated sequencer traces using phred. II. Error probabilities. Genome Res. 8, 186-194.

21. Ewing, B.; Hillier, L.; Wendl, M. C.; Green, P. (1998). Base-calling of automated sequencer traces using phred. I. Accuracy assessment. Genome Res. 8, 175-185.

22. Friesen, H.; Humphries, C.; Ho, Y.; Schub, O.; Colwill, K.; Andrews, B. (2006). Characterization of the yeast amphiphysins Rvs161p and Rvs167p reveals roles for the Rvs heterodimer in vivo. Mol. Biol. Cell $17,1306-1321$

23. Furlaneto, M. C.; Pizzirani-Kleiner, A. A. (1992). Intraspecific hybridization of Trichoderma pseudokoningii by anastomosis and protoplast fusion. FEMS Microbiol. Lett. 90, 191-196.

24. Glass, N. L.; Dementhon, K. (2006). Non-self recognition and programmed cell death in filamentous fungi. Curr. Opin. Microbiol. 9, 553-558.

25. Glass, N. L.; Jacobson, D. J.; Patrick, K. T. S. (2000). The genetics of hyphal fusion and vegetative incompatibility in filamentous ascomycete fungi. Annu. Rev. Genet. 34, 165-186.

26. Glass, N. L.; Kaneko, I. (2003). Fatal attraction: nonself recognition and heterokaryon incompatibility in filamentous fungi. Eukaryot. Cell 2, 1-8.

27. Gordon, D.; Abajian, C.; Green, P. (1998). Consed: a graphical tool for sequence finishing. Genome Res. 8, 195-202.

28. Gourlay, C. W.; Ayscough, K. R. (2006). Actin-induced hyperactivation of the Ras signaling pathway leads to apoptosis in Saccharomyces cerevisiae. Mol. Cell. Biol. 26, 6487-6501.

29. Hammil, T. M. (1974). Electron microscopy of phialides and conidiogenesis in Trichoderma saturnisporum. Am. J. Bot. 61, 15-24.

30. Jacobson, D. J.; Beurkens, K.; Klomparens, K. L. (1998). Microscopic and ultrastructural examination of vegetative incompatibility in partial diploids heterozygous at het loci in Neurospora crassa. Fungal Genet.Biol. 23, 45-56.

31. Luzzani, C.; Cardillo, S. B.; Moretti, M. B.; García, S. C. (2007). New insights into the regulation of the Saccharomyces cerevisiae UGA4 gene: two parallel pathways participate in carbon-regulated transcription. Microbiology 153, 3677-3684.

32. Marek, S. M.; Wu, J.; Glass, N. L.; Gilchrist, D. G.; Bostock, R. M. (2003). Nuclear DNA degradation during heterokaryon incompatibility in Neurospora crassa. Fungal Genet. Biol. 40, 126-137.

33. Menna, P.; Hungria, M.; Barcellos, F. G.; Bangel, E. V.; Hess, P. N.; Martínez-Romero, E. (2006). Molecular phylogeny based on the $16 \mathrm{~S}$ rRNA gene of elite rhizobial strains used in Brazilian commercial inoculants. Syst. Appl. Microbiol. 29, 315-332.

34. Moretti, M. B.; Perullini, A. M.; Batlle, A.; Garcia, S. C. (2005). Expression of the $U G A 4$ gene encoding the $\delta$-aminolevulinic and $\gamma$ aminobutyric acids permease in Saccharomyces cerevisiae is controlled by amino acid-sensing systems. Arch. Microbiol. 184, 137-140.

35. Nadalini, M. F. C. (1997). Caracterização genética e produção de celulases em Trichoderma pseudokoningii. Rio Claro, Brasil, 142p. (Ph.D. Thesis. Instituto de Biociências do Campus de Rio Claro, Universidade Estadual Paulista).

36. Paccola-Meirelles, L. D.; Azevedo, J. L. (1991). Parasexuality in Beauveria bassiana. J. Invertebr. Pathol. 57, 172-176.

37. Pe'er, S.; Chet, I. (1990). Trichoderma protoplast fusion: a tool for improving biocontrol agents. Can. J. Microbiol. 36, 6-9.

38. Pecchia, S.; Anné, J. (1989). Fusion of protoplast from antagonistic Trichoderma harzianum strains. Acta Hort. 255, 303-311.

39. Pontecorvo, G. (1956). The parasexual cycle in fungi. Annu. Rev. Microbiol. 10, 393-400.

40. Pontecorvo, G.; Roper, J. A. (1952). Genetic analysis without sexual reproduction by means of polyploidy in Aspergillus nidulans. J. Gen. Microbiol. 6, 7-8.

41. Pontecorvo, G.; Roper, J. A.; Forbes, E. (1953). Genetic recombination without sexual reproduction in Aspergillus niger. J. Gen. Microbiol. 8, 198-210.

42. Raeder, U.; Broda, P. (1985). Rapid preparation of DNA from filamentous fungi. Lett. Appl. Microbiol. 1, 17-20.

43. Robson, G. D. (2006). Programmed cell death in the aspergilli and other filamentous fungi. Med. Mycol. 44, S109-S114.

44. Sarkar, S.; Iyer, G.; Wu, J.; Glass, N. L. (2002). Nonself recognition is mediated by HET-C heterocomplex formation during vegetative incompatibility. EMBO (Eur. Mol. Biol. Organ.) J. 18, 4841-4850.

45. Saupe, S. J. (2000). Molecular genetics of heterokaryon incompatibility in filamentous ascomycetes. Microbiol. Mol. Biol. Rev. 64, 489-502.

46. Silva, I. F.; Pizzirani-Kleiner, A. A. (1999). Caracterização genética por RAPD de recombinantes em Trichoderma pseudokoningii. Summa Phytopathol. 25, 233-239. 
47. Sivan, A.; Harman, G. E.; Stasz, T. E. (1990). Transfer of isolated nuclei into protoplasts of Trichoderma harzianum. Appl. Environ. Microbiol 56, 2404-2409.

48. Stasz, T. E.; Harman, G. E. (1990). Nonparental progeny resulting from protoplast fusion in Trichoderma in the absence of parasexuality. Exp. Mycol. 14, 145-159.

49. Stasz, T. E.; Harman, G. E.; Gullino, M. L. (1989). Limited vegetative compatibility following intra and interspecific protoplast fusion in Trichoderma. Exp. Mycol. 13, 364-371.

50. Stasz, T. E.; Harman, G. E.; Weeden, N. F. (1988). Protoplast preparation and fusion in two biocontrol strains of Trichoderma harzianum. Mycologia 80, 141-150.

51. Stoval, M. E. (1992). Interstrain spheroplast fusion of Alternaria alternata. Appl. Microbiol. Biotechnol. 37, 480-484.

52. Tanaka, Y.; Murata, N.; Kato, H. (1979). Behavior of nuclei and chromosomes during ascus development in the mating between either rice - strain or weeping lovegrass - strain and ragi - strain of Pyricularia. Ann. Phytopathol. Soc. Jpn. 45, 182-191.

53. Uemura, T.; Tomonari, Y.; Kashiwagi, K.; Igarashi, K. (2004). Uptake of GABA and putrescine by UGA4 on the vacuolar membrane in Saccharomyces cerevisiae. Biochem. Biophys Res. Commun. 315, $1082-$ 1087 